Results At baseline, 150 (46.4\%) in group B reported condom use at their last sex act compared to $174(59.0 \%)$ in group A ( $p=0.002)$. Reported consistent condom use at last sex act was significantly higher in group A compared to group B (53.3\% vs. 46.7\%, p = 0.01). $\mathrm{HIV}+$ status awareness did not predict condom use over time [odds ratio (OR):1.2; 95\% confidence interval (CI): 1.9-1.5; $\mathrm{p}=0.15]$.

Male patients were more likely to use condoms at last sex act (OR: 2.7; 95\% CI: 2.2-3.43; p < 0.01). Older patients (OR: 0.8; 95\% CI: $0.7-0.8 ; p<0.01$ ), being never married (OR: $0.7 ; 95 \%$ CI: $0.5-$ $0.9 ; \mathrm{p}=0.01$ ); divorced (OR: 0.5; 95\% CI: 0.3-0.9; $\mathrm{p}=0.01$ ); and under the influence of alcohol during their last sex act (OR: 0.3; 95\% CI: $0.2-0.4 ; p=<0.001)$ were less likely to use condoms at their last sex act.

Conclusion Knowledge of HIV+ status is significantly associated with consistent condom use. Age, gender, marital status and alcohol consumption are significant predictors of condom use during last sex act.

\section{P4.072 SEXUAL RISK AND PREVENTIVE BEHAVIOURS AMONG YOUNG PEOPLE IN NIGERIA}

doi:10.1136/sextrans-2013-051184.0970

\section{T Jide-0jo. Dawn's Image Consult, Lagos, Nigeria}

Background Young people, especially teenagers, between 12 and 19 years are very vulnerable and very susceptible to different kinds of behaviours, most of which are risky and destructive in nature thereby hazarding their lives. Some of them are their engagement in unprotected sex, illicit drugs taking, smoking, alcoholism etc. risky behaviours make them vulnerable HIV and STI. From previous experience, more young people are getting infected which makes the study imperative.

Methods 5 high schools were selected from Ojo Local Government Area of Lagos State, South- Western Nigeria. Official permissions were sought and obtained from the schools to allow students to participate. 50 samples from each school. Samples for study were randomly selected. Descriptive and inferential statistics were used to analyse the collected data.

Results The findings of the study revealed that a significant number of these young people who have had sex and/or are sexually active were introduced into the act by friends and peers. Their chief motivating factor is desire for peer acceptance. The abstainers are so because family, religious beliefs and personal convictions because of their goals which they felt sexual involvement was a distraction. These were the ones with high self-esteem. They were assertive in their relationships and declared boundary lines.

Conclusion Despite awareness and sensitization going on, we discover that young people still engage in risky behaviours which make them prone to STIs and HIV infections. There is therefore a need for advocacy for life skills building for young people that will enable them to effectively manage relationships. This will be in form of assertiveness and self-esteem building in them.

\section{P4.073 PREVENTION OF HIV/AIDS INFECTIONS AMONG FEMALE COMMERCIAL SEX WORKERS IN KAMPALA, UGANDA}

doi:10.1136/sextrans-2013-051184.0971

R Nerima. Elizabeth Glaser Pediatric AIDS Foundation, Kampala, Uganda

Introduction The Kawempe Health Development project located in a poor informal urban setting of kampala aimed to improve sexual and reproductive health services available to female commercial sex workers and equip them with employable skills for behavioural change. The review was conducted to assess project impact on increasing SRH services uptake among sex workers and document changes in their demand for adopting safe sex behavioural change.
Study methodology This retrospective and cross-sectional study was conducted in July 2012 and reviewed project information from 2001 to 2009. The combined study design was intended to facilitate a more in-depth analysis of issues, taking into consideration the perspective of project key stakeholders. Both quantitative and qualitative data was generated with descriptive analysis methods and thematic analysis being used, respectively.

Outcomes The study observed a steady increase in service uptake for VCT from a monthly average of 51 in 2001 to 96 in 2009, representing an $88.2 \%$ increase, with proportion of HIV positive Sex workers declining from $16 \%$ in 2001 to $8 \%$ in 2009. Use of family planning methods and treatment of STI and opportunistic infections accessed through the project facility increased from $26 \%$ to $40 \%$. Qualitative data confirmed improved negotiation for safer sex and use of male condoms during the project period 2001 to 2009. Free vocational skills training to sex workers were in great demand and it created opportunities for alternative income. However, lack of start-up capital limited the number of trained Sex workers who could quit the sex trade.

Recommendation Need to strengthen institutional and financial sustainability to match the increasing demand for SRH services and vocational skills training for sex workers. This may be through formation of partnerships and mainstreaming project activities into ongoing health programmes.

\section{P4.074 KNOWLEDGE AND ATTITUDES OF NURSING STUDENTS REGARDING HIV AND PEOPLE LIVING WITH HIV}

doi:10.1136/sextrans-2013-051184.0972

${ }^{1} \mathrm{G}$ Kayaert, ${ }^{2}$ S A T Van den Eynde, 'A Deschamps. 'Katholieke Hogeschool Leuven, Leuven, Belgium; ${ }^{2}$ Sensoa, Antwerp, Belgium

This research investigated the knowledge and attitude of nursing students regarding HIV transmission risks at their workplace. An online questionnaire was completed by 157 students, mostly between 19 and 23 years old, following a bachelor education in Leuven, a middle sized Belgian town.

Generally, the majority of the students overestimated the risks of hiv transmission. Situations like eating in a restaurant where the cook has hiv, sharing cutlery, plates or glasses with a person living with hiv or working alongside someone living with hiv, were all considered to hold a risk of transmission by respectively $62 \%$ en $50 \%$ of the respondents. Also, only $51 \%$ of all respondents knew that hiv is not transmitted through saliva.

Half of the student has, at some point during their last internship, worried about contracting hiv, and $84 \%$ of the students advocates regular testing of all nursing staff working at a hospital. 19\% believes that hiv-positive nurses should stop nursing patients, and one in three students state they have a right to know the positive hiv serostatus of their colleagues, even if this goes against the wishes of this colleague. Also, 36\% of the nursing students claims that nurses have the right to refuse caring for an hiv-positive patient.

The findings show that nursing students over estimate the risk of hiv transmission in their workplace. Also they hold discriminating attitudes which might hamper equal treatment of people living with hiv in regular care facilities. We therefor recommend the implementation of educational interventions in nursing students' training curricula focussing on knowledge and attitudes on hiv and people living with hiv.

\section{P4.075 THE IMPORTANCE OF ALCOHOL AND PEERS IN RISKY SEXUAL PARTNER SELECTION}

doi:10.1136/sextrans-2013-051184.0973

S A S Staras, M D Livingston, F Weymar, K A Komro. University of Florida, Gainesville, FL, United States 